\title{
AN OVERVIEW OF AI ENABLED M-IOT WEARABLE TECHNOLOGY AND ITS EFFECTS ON THE CONDUCT OF MEDICAL PROFESSIONALS IN PUBLIC HEALTHCARE IN PAKISTAN
}

\author{
Abdul Samad Dahri \\ Business Administration and Social Sciences \\ Mohammad Ali Jinnah University, Karachi, (Pakistan). \\ E-mail: dahriabdulsamad@gmail.com ORCID: https://orcid.org/0000-0003-4517-3493 \\ Shafiq-ur-Rehman Massan \\ QEC and Co-ordination \\ Mohammad Ali Jinnah University, Karachi, (Pakistan). \\ E-mail: srmassan@hotmail.com ORCID: https://orcid.org/0000-0001-6548-6513 \\ Liaquat Ali Thebo \\ Department of Computing, \\ Mohammad Ali Jinnah University, Karachi, (Pakistan). \\ E-mail: liaqaut.ali@jinnah.edu ORCID: https://orcid.org/0000-0001-7097-5610
}

Gitación sugerida:

Dahri, A. S., Massan, S.-U.-R., y Thebo, L. A.(2020). An overview of AI enabled M-IoT wearable technology and its effects on the conduct of medical professionals in Public Healthcare in Pakistan. 3C Tecnología. Glosas de innovación aplicadas a la pyme, 9(2), 87-111. http://doi.org/10.17993/3ctecno/2020.v9n2e34.87-111 


\section{ABSTRACT}

Interconnectivity of smart devices such as mobile technology adoption in healthcare holds humongous impacts. Yet, medical professionals are reluctant to reap potential benefits of technology and the reason behind this phenomenon is ambiguous. This study aims to highlight current critical conditions in public healthcare hospitals in Pakistan, and how IoT will add value in healthcare services effectiveness through mobile computing and also to indicate current concepts that may add value in over-all smart healthcare system. According to available information, study to on AI enabled M-IoT network-based healthcare system specially in developing countries to address healthcare problems are rarely known. This study empirically analyzed the factors that influence IoT based smart healthcare devices adoption in Pakistan. In understand the phenomenon, Partial Least Square Equation Model (PLS SEM) was used to understand the relational influence of performance expectance, effort expectance, and social influence over behavior to use through intention to use the technology supported by Unified Theory of Acceptance Technology (UTAUT) assumptions. The results show that clinicians are reluctant to use technology though the results also reveal that same clinicians have positive influence of performance and effort expectations on their intention to use technology that leads the actual behavior of using the technology. Though, this research is among few to beacon upon urgent focus of public healthcare management in developing countries. Yet, new research is lacking far behind to facilitate methods to opt for M-IoT healthcare devices powered by AI.

\section{KEYWORDS}

Artificial Intelligence (AI), Internet of Things (IoT), Technology proliferation, Unified Theory of Acceptance Technology (UTAUT), Coronavirus (COVID-19), Healthcare. 


\section{INTRODUCTION}

The ongoing pandemic of corona virus has become one of the biggest threats to global economy and especially healthcare. Healthcare is backbone to any nations' development and growth (Samad, Memon, \& Kumar, 2020). It is always the healthcare facilities that serves when the state is faced with critical public healthcare risk. Whether it be the eradication of Smallpox globally, Polio from USA, Cholera in Asia claiming 100,000 deaths, Bubonic plague in China claiming 12 million deaths and Coronavirus also known as "COVID-19" outbreak in Wuhan district of China, which has become a global public healthcare risk. According to Centers for Disease Control and Prevention, the Coronavirus (COVID-19) was reported on 30th January 2020 in USA as well. With reference to ongoing spread of COVID-19 besides its exponential negative impact ranging from service, manufacturing, stock market and oil prices to Gross Domestic Product of countries globally (see Figure 1) as well as it has become global health risk by sickening more than 482,800 people and claimed 21,896 deaths in more than 171 countries globally.

Though, before COVID-19, healthcare was in chronic crises mainly of doctor and nurse's shortage, burnout of physicians and high demand for enduring care (Meskó, Hetényi, \& Győrffy, 2018). But global healthcare systems were never in such a desperate condition ever before. In china for instance, hospitals were maxed out and basic medical supplies such as gloves were empty and lead to shutdown of public life at all levels (Wallace-Wells, 2020).

Therefore, for an effective healthcare system needs the availability, accessibility, acceptability and quality of its healthcare workforce (World Health Organization, 2013). World Health Organization (WHO) (2013) estimated problem of aged workforce with need-based healthcare workforce shortage globally by 17.4 million? Whereas, high frequency of patients and shortage of medical staff overloads physicians while increasing burnout experience (Meskó et al., 2018).

As a result, lack of access to healthcare by masses and compromised quality in healthcare facilities is common globally. According to Meara et al. (2015), 400 million people lack to one or more essential 
health services and 5 billion people do not have access to safe and affordable surgical and anesthesia care when needed. According to Bernaert and Dimitrova (2017), at World economic, 9 billion people will need healthcare services by 2050 . While, staggering $\$ 142.6$ billion were invested for developing countries' healthcare targets which no government could achieve. Moreover, global healthcare is $\$ 300$ billion healthcare question that needs accurate spending. Since, 20\% of healthcare spend is wasted globally and top 15 countries waste $\$ 1100$ to $\$ 1700$ on an average. Which is above the average (\$120/ person) spent on healthcare of more than 50 bottom countries (Bernaert \& Akpakwu, 2018). According to Malkani (2016) in this context, reported healthcare sector being ignored by the government and policies and practices lack efficient implementation and virtually absent in case of Pakistan. Thus, new approaches and eloquent work to ventilate vital healthcare services is the need of the hour.

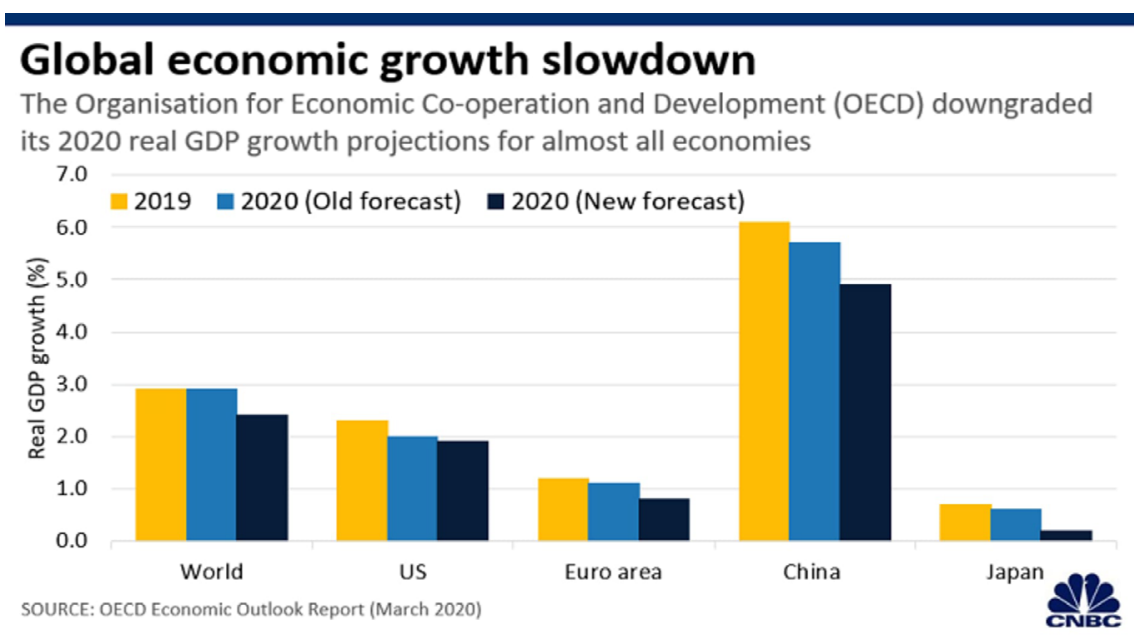

Figure 1. Global Economic Growth Slowdown.

According to UN (2018) report, 90\% of the global population lives in the rural areas, and this number will reach to its peak by 2020. Where, life expectancy is worse, limited access to healthcare facilities, lack of trained healthcare workers, transport difficulty and so on, contribute to low quality of healthcare among rural population (Strasser, Kam, \& Regaldo, 2016). Besides, that skyrocketing costs, high priced 
drugs, hospital-acquired infections, and failure of to deliver healthcare boost adverse healthcare events. Specially in developing countries like Pakistan where doctor to patient ratio is 1: 1300, doctor to nurse is 1: 2.7 (Khan, 2019) nurse to patient ratio is 1:12411 patients (Zaidi, 2012), and only 22\% of patients are served through public hospitals (Solangi et al., 2017b)

Since, now a days, production, application and utilization of information technology demarks difference between developed and developing countries (Ajami, Ketabi, \& Torabiyan, 2015). The workflow of hospital may vary from patient to patient, population problem, poor healthcare services and scarcity of healthcare resources, where working conditions are exceptionally uncertain, unscheduled, and care decentralized for instance COVID-19 pandemic, craves for the utilization of information technology (Nazir et al., 2019).

The healthcare information technology (HIT) development holds potential to improve healthcare quality and accuracy in emergency, safety, medical errors, efficiency, and patient care (Rothenhaus et al., 2009).Therefore, the immediate innovative intervention is needed in rural areas of developing countries (Samad, Al-Athwari, \& Hussain, 2019). Where, managers could use medical equipment and new technological tools to improve patient safety and satisfaction (Birgani \& Asadpoor, 2011).

Similarly, the development of hospital information systems accompanied with gradual advancement of software, hardwires, and new methods in order to enhance agility and quality of healthcare services is growing (Siamian et al., 2005). The increased population and scarcity of healthcare resources necessitates the adoption of IoT serves the best solution in terms of cost and efficiency (Tyagi, Agarwal, \& Maheshwari, 2016).

Post 80s and 90s, Kevin Ashton in 1999 initiated term Internet of Things (IoT), referring as uniquely identifiable connected objects with radio-frequency identification (RFID) technology. IoT basically observes interconnectivity of devices as data sources through existing internet infrastructure (Shaikh, 2019). IoT and technological advances in healthcare services to patients not only reduce errors, increase 
agility and accuracy in healthcare quality, but also, lowers costs through information integration (Malliarou \& Zyga, 2009). Therefore, it is worth acknowledging the role of every healthcare department in hospital, recognize the importance of IoT integration in healthcare and to improve quality and reduce cost of emergency department and related provisional units in hospitals (Mirhoseinie et al., 2014).

Recent developments in IoT unleashed unprecedented potential in business world (see Figure 1). According to Global Forecast, IoT healthcare market is expected to grow from US $\$ 55.5$ billion to US $\$ 188.0$ billion by 2024 at an annual compound growth rate of $27.6 \%$. This is due to active patient healthcare monitoring, patient centric management and high speed network technologies for IoT connectivity (Singh, n.d.).

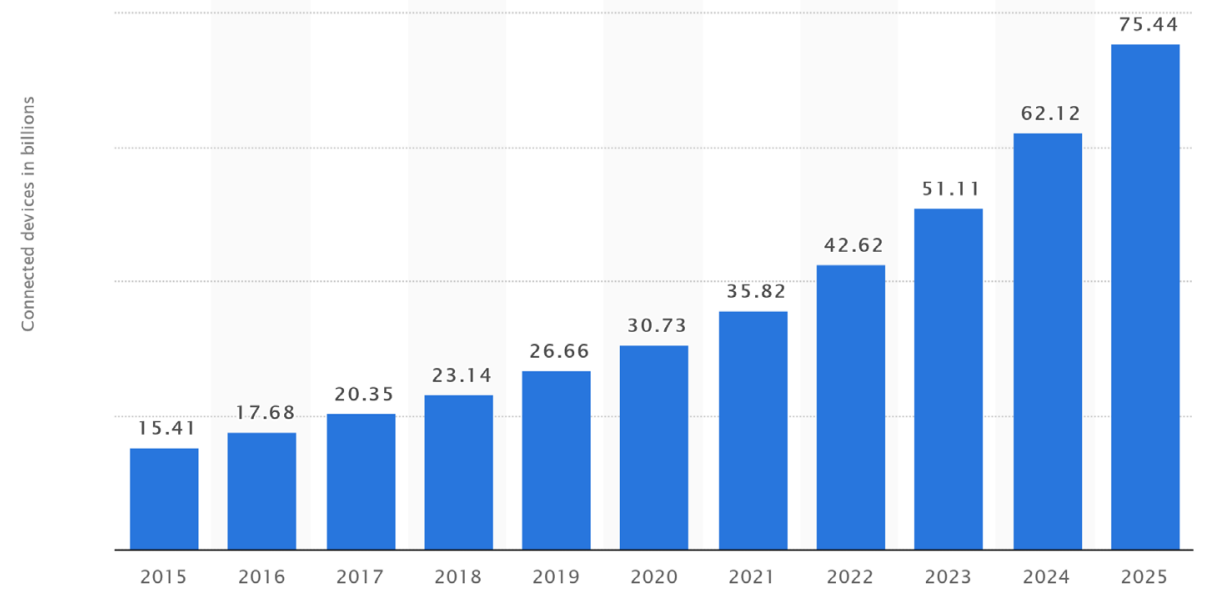

Figure 2. Source - Statista Research Department, Nov 14, 2019.

At present various tools and methods are used to quantify the healthcare performance. Accordingly Van der Meulen (2017) reported a forecast that the IoT will connect 26 billion units till 2020. IoT brings rich user experience, connectivity, reliability and smart healthcare services to patients (Islam et al., 2015), 
which leads to smart healthcare system (see Figure 2) composed of smart functionality, remote server, and the network to remotely monitor patients (Yuehong et al., 2016). On a recent note, $76 \%$ healthcare organizations believe that IoT will transform healthcare industry (Anurina, 2019).

Similarly, to address this problem, mobile technology provides grounds for IoT by using mobile phones, IP connectivity, lower power consumption, security, apps, or through m-health care system (Nazir et al., 2019). Mobile computing is new trend involved in many areas including healthcare providing quality processing, storage, information and query to the users at remote geographical areas. Where, IoT serves as an intelligent sensing technology that supports vitally in sending and receiving mobile medical data (Ma et al., 2018).

Currently, most of the mobile-health applications are used by healthcare professionals for various tasks (Elazhary, 2019). For instance, m-health and m-learning. Where, m-health apps are used for diagnosis of diseases, drug references, and medical computations. Therefore, using M-IoT devices in healthcare will reduce cost and improve effectiveness of healthcare system.

One of the most important use of m-health app is in PHS-personalized health system, where various sensors in mobile such as gyroscope, accelerometer, altimeter, general packet radio service (GPRS), 4G systems, global positioning system (GPS) and blue-tooth technology integrated with IoT environment will collectively help monitor, diagnose, or even forecast health risks at a distance (Qi et al., 2017). Or these sensors separately may be attached to body of patient (ankle, wrist, and chest) and collect data through mobile app and sent it to respective department or doctor (Subasi et al., 2018).

The technological adoption in the healthcare paced the information flow between doctor and patient pilling up twice every three years for which an estimated reading time for physician to remain up to date is 29 hours straight which is impossible (Curioni-Fontecedro, 2017). This adds critical call for more advanced computational power to smart devices used in healthcare system such as Artificial Intelligence 
(AI) agents to enhance the predictiveness in healthcare workflow (Bui, 2000), improve quality and lower costs for patient care.

An AI enabled system uses sophisticated algorithm to 'learn' and extract useful information from a large patient population to assist in making real-time inferences for healthcare outcomes. Moreover, there are more than $97000 \mathrm{AI}$ enables mobile healthcare ( $\mathrm{mHa}$ ) available on google play store and Apple store and these would be downloaded by 500 million people globally till 2015 (Jahns \& Houck, n.d.), while, 50\% of these apps will be downloaded in smart phones by 2017 (Siltala, 2013). This phenomenon progressively has turned smartphones into medical kits for real-time healthcare monitoring for patient activities, early predictability, disease screening, improved medication adherence (Alemdar \& Ersoy, 2010) by medical professional and minimized medical errors that are inevitable in human clinical practices (Pearson, 2011).

Moreover, healthcare data is broadly classified into non-AI and AI systems. Though, non-AI data uses less complex computational process, is gradually replaced by $\mathrm{AI}$ enabled systems due their in-efficiencies. AI based platforms (applications) which are mostly hybrid in nature and involve AI Neural Networks (ANNs), Fuzzy theory, and evolutionary algorithms (Sannino et al., 2019). For example, Dargazany, Stegagno, and Mankodiya (2018) introduced the concept of wearable deep learning (WearDL) which is unifying conceptual architecture inspired by human nervous system that offered inclusion of deep learning, IoT, and wearable technologies. Where, brain was conceptualized as deep learning for cloud computing and big data processing, the spinal cord as IoT for fog computing and big data transfer, and the peripheral sensory and motor nerves as wearable technologies as edge devices for big data collection (Sannino et al., 2019). Although, these techniques are theoretically sound yet lack potential practical explorations. 


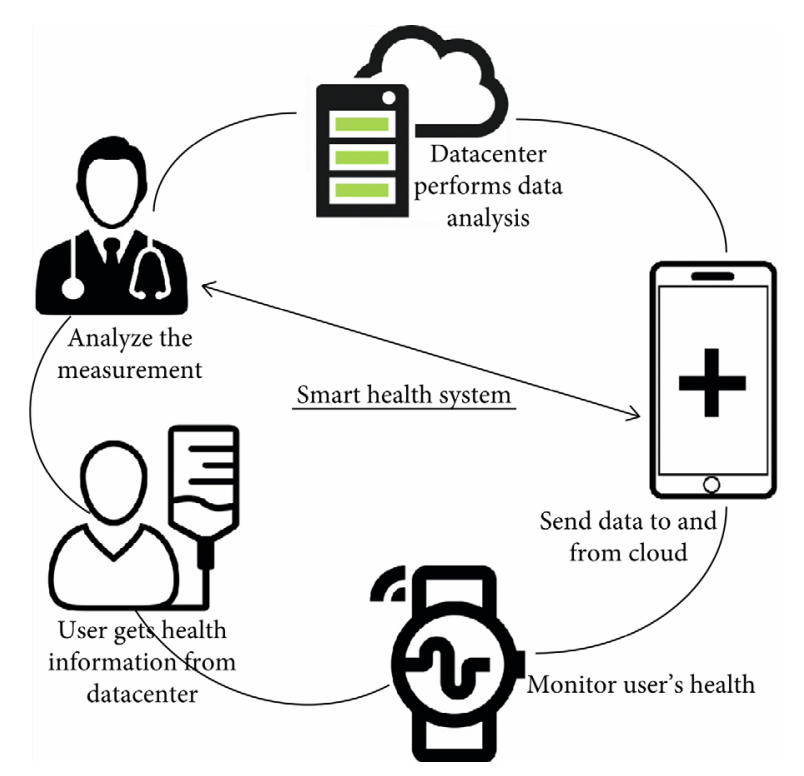

Figure 3. M-loT Warble Smart Healthcare System.

Advantageously, over 85\% of global population is under wireless signal (World Health Organization, 2013), 80\% of them hold smartphones (Chaffey, 2019), and in developing countries like Pakistan over 90\% users have 2G internet (PTA annual report 2014-2015). These smartphones with m-health apps enable patients to use healthcare applications to monitor their health indicators and diseases (Karaca et al., 2019) and categorized into single condition apps which are developed for specialized diseases and cluster condition applications which treat certain disease together. Based on literature, few of these applications are discussed below:

\section{Single condition Applications:}

Glucose Level Sensing: This app is helpful for Diabetes patients whose glucose level sustains at higher levels than normal. Through blood glucose monitoring system suggests best meal, exercise and medicine time to the patient. Doctors may propose a noninvasive glucose measuring m-IoT method on actual basis. In this method, sensor attached to patient body serves as IoT device and transmits real time 
information to respective department or doctor. This device is equipped with blood glucose collector, smartphone, and a processor.

Blood Pressure Monitoring System: Blood pressure (PB) is force by heart to circulate blood in body. An IoT medical device can assure monitoring of $\mathrm{Bp}$, glucose level in blood, and any irregularity can also be transmitted supported by IoT network.

Body Temperature Monitoring System: monitoring and maintaining body temperature is an important element of healthcare. From m-IoT perspective, temperature varies from body to body yet gives accurate readings and assists in infrared detection and RFID module.

Oxygen Saturation Monitoring System: device named pulse oximeter measures oxygen saturation level in the blood. The use of IoT with pulse oximeter benefits technology-based healthcare applications on wrist. This is a low power, low cost, Bluetooth enabled device that connects with IoT network which enables doctor or respective department to monitor patient remotely.

Electrocardiogram (ECG) Monitoring system: This device can display the ECG waves on the user. This device generates specific ECG bio-signal reports of the patient and link this information to respective user by integrating with IoT network. IOIO-OTG is micro controller that converts ECG analog signals into digital data in binary numbers which can be monitored on IoT network. This device can be very helpful for hospitals / ED as it helps in detecting any anomalies in the patient health condition in advance and reduces wait time at hospitals.

\section{Gluster Condition Application:}

Wheelchair Management System: keeping in view of elderly and disabled patients, smart wheelchairs are recommended by health experts. These wheelchairs are enabling location, movement and status of the user and links it with IoT network, helping respective users in monitoring patients. 
Rehabilitation System: IoT can help rehabilitation system regarding population growth and lack of health expertise. Body sensor network can improve the abilities of the disabled person through IoT networks that would enhance rehabilitation system. Number of rehabilitation system for example smart city rehabilitation and integrated application system for prisoners (Islam et al., 2015).

Healthcare Solutions Using Smartphones: Currently, smartphones are equipped with sensors and electronic control applications. In the healthcare field smartphones provided real-support and monitoring and communication between patient and respective department or physician. Few of smartphone m-healthcare apps include; blood pressure watches which is smart wrist band connected with smartphone and gathers blood pressure data. Another one is, heart rate monitors that measures and records heart related data. Health assist is also m-health app that keeps record of bloom-health app that keeps record of blood pressure, heart rate, body temperature and other designated physical activities.

Regrettably, in general, it is observed in the healthcare sector that usage of technology by doctors across the nation for various medical and investigative techniques, is not best fitted with technological healthcare framework globally (Solangi et al., 2017a). Moreover, negative attitude towards technology adoption is also observed among healthcare professional which directs significant concerns towards acceptance and efficient use of technology (Mitzner et al., 2010). Followed by Safi, Thiessen, and Schmailzl (2018) who reported medical professionals avoided using technologic fearing mass control by management. Since, negative attitude of medical professionals using technological devices in healthcare may delay fruits of $\mathrm{m}-\mathrm{IoT}$ in healthcare system.

Similarly, various problems are linked with future structure of healthcare for embracing m-IoT innovations, specially getting doctors and healthcare services on standby for global uncertain calamities such as COVID-19. Indirect Emergency Healthcare (IEH) for instance, keeping these conditions on hand, a dedicated service called indirect emergency healthcare offers varying solutions to these situations including information availability, alter information, post-accident action, and record keeping. These problems require novel investigation to establish m-IoT smart healthcare system for remote patient 
assistance, monitoring, early diagnosis, and early treatment, especially in less privileged areas of developing nations.

Therefore, this research leads to utilize standard constructs of technology acceptance model (TAM) to understand the relevance and attainability of m-IoT based smart healthcare system. The technological acceptance model (TAM) is grounded on the idea of social psychology use as a gage to illustrate and asses the behavior of users to utilize innovation. TAM is used for best quality level (Bagozzi, 2007). The refined version of TAM is Unified theory of acceptance and use of Technology (UTAUT) which has been quite effective to measure the factors that determine use behavior of technology in the healthcare consumers (Venkatesh et al., 2003). The UTAUT theory is inclusion of Innovation Diffusion Theory (IDF), Theory of Planned Behavior (TPB), Social Cognitive Theory (SCT), Motivation Model (MM), Theory of Reasoned Action (TRA), Model of Personal Computer Utilization (MPCU), and TAM itself to better understand the acceptance and usage of new technology.

Since, UTAUT model proved valuable framework to understand behavioral aspect of technological acceptance and utilization in different cultures over short period of time. The UTAUT model measures the behavior $(\mathrm{BU})$ of technology through behavioral intention $(\mathrm{BI})$ of technology use influenced by four determinants namely, performance expectancy (is the degree of worth performing a task to achieve set goals), effort expectancy (is the ease associated with use), social influence (social importance linked with new system utilization), and facilitating conditions (one's believe of technological and organizational infrastructure exists for support) (Venkatesh, Thong, \& Xu, 2016). Specially, Pakistan has underdeveloped technical and infrastructure support system (Kurji, Premani, \& Mithani, 2016). Based on UTAUT theory to examine its relevance and practicability in the field of M-IoT healthcare system. Since, in healthcare technological adoption behavior is at individual level, therefor, performance expectancy, effort expectancy, and social influence determinants are used based on UTAUT to understand behavioral intention towards utilization of M-IoT in public and private healthcare sector. 


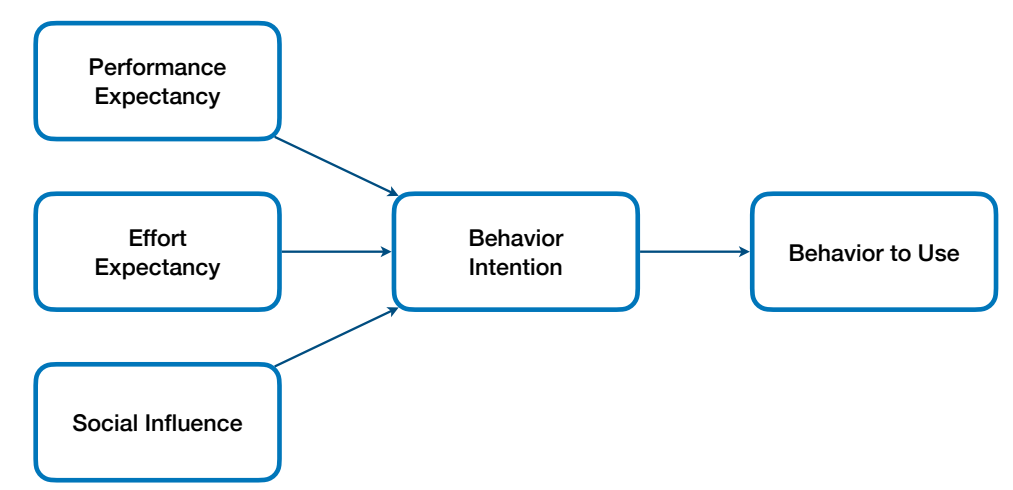

\section{MATERIAL AND METHODS}

Population for this study comprised of over 479 (Bureau of statistics planning \& development department government of Sindh, 2016), including dentists, physicians, and gynecologist and surgeons in Sindh public hospitals, out of which 9 medical professionals were unclear on using wearables M-IoT healthcare devices. Remaining population (who understood m-health applications and IoT wearable devices) of 470 healthcare professionals following Krejcie and Morgan (1970) model for a minimum sample of 214 was selected for data collection on random bases. The study uses questionnaire of acceptance of technology adapted from previously validated instrument by Cimperman, Makovec, and Trkman (2016) as this scale specifically addresses home telehealth devices, to focus on M-IoT applications on determinants of behavioral intention to use M-IoT technology. It comprises of one part for participants' demographics and second part including 15 items for UTAUT determinants for performance expectancy (PE), effort expectancy (EE), and social influence (SI) on behavioral of use (BU) of using new technology, through behavioral intention (BI), where the answers were recorded on 7-point frequency Liker scale. Since, incomplete responses were screened, the final sample for analysis was of 185 responses that belonged to age group of 20 to 40 years mainly female $(74 \%)$ and male $(36 \%)$. They were graduates $(68 \%)$ and undergraduates (42\%), with work experience ranging from 2 years to 40 years in field of Sindh province of Pakistan. 


\section{RESEARCH FINDINGS}

\subsection{RESULTS OF MEASUREMENT MODEL}

For measurement model, convergent validity and discriminant validity values were evaluated.

\section{Convergent validity}

Convergent validity is the degree of latent variables correlated with other variables items (Hair et al., 2016). Following Henseler et al. (2014) factor loadings, average variance extracted (AVE) and composite reliability (CR) were assessed. Further, factor loading threshold of 0.6 was achieved (see Figure 1 outer loadings and t-values), for AVE values were above 0.5 , and CR values were also above 0.7 on recommended threshold by Chin (1998); Nunnally and Bernstein (1994); and Hair et al., (2011) (see Table 1).

\section{Discriminant Validity}

Discriminant validity is simply the distinctiveness among the constructs. Following Henseler, Ringle, Sarstedt (2015) Hetero-Trait-Mono-Trait (HTMT) ratio of correlation was evaluated. For HTMT threshold values should be below 0.9 recommended by Gold and Arvind Malhotra (2001) along with confidence interval for better significance assessment which should be less than 1 (Henseler et al., 2015). Table 1 reveals achievement of all suggested criterion for discriminant validity.

Table 1. Hetero-trait-mono-trait (HTMT), CR, AVE ( $\mathrm{N}=185)$.

\begin{tabular}{|c|c|c|c|c|c|c|c|}
\hline Variable & PE & EE & SI & BI & BU & CR & AVE \\
\hline PE & 1 & & & & & 0.821 & 0.641 \\
\hline EE & 0.042 & 1 & & & & 0.844 & 0.66 \\
\hline SI & 0.057 & 0.047 & 1 & & & 0.798 & 0.611 \\
\hline BI & 0.012 & 0.048 & 0.055 & 1 & & 0.804 & 0.638 \\
\hline BU & 0.081 & 0.078 & 0.057 & 0.039 & 1 & 0.884 & 0.617 \\
\hline
\end{tabular}


Note: Performance Expectancy (PE), Effort Expectancy (EE), Social Influence (SI), Behavioral intention (BI), and Behavioral of Use (BU).

\section{MEASURES AND METHODS}

Hair et al. (2016) recommended R2, standard beta, t-values via bootstrapping procedure on 5000 samples for predictive relevance $\mathrm{Q}_{2}$ and the effect size f2. Moreover, confidence interval values were also taken into consideration which ensures the confidence of same response from same sample of target population as revealed in Table 2 below.

Table 2. Results of Structural model Assessment.

\begin{tabular}{|c|c|c|c|c|c|c|c|}
\hline Path & Beta & St. Dev & T Stats & P Values & R2 & f2 & Q2 \\
\hline PE -> BI & 0.459 & 0.112 & 4.098 & 0.000 & 0.524 & 0.267 & 0.139 \\
\hline EE -> BI & 0.126 & 0.023 & 5.478 & 0.001 & 0.494 & 0.248 & 0.238 \\
\hline SI -> BI & -0.013 & 0.068 & 0.195 & 0.849 & & 0.152 & \\
\hline BI-UB & 0.326 & 0.07 & 4.639 & 0.000 & & 0.251 & \\
\hline PE-BI-UB & 0.096 & 0.029 & 3.288 & 0.001 & & & \\
\hline EE-BI-UB & 0.121 & 0.034 & 3.567 & 0.002 & & \\
\hline SI-BI-BU & 0.035 & 0.016 & 2.187 & 0.001 & & \\
\hline
\end{tabular}

Table 2 above, reveals that $\mathrm{PE}$ is significantly related to $\mathrm{BI}(\mathrm{b}=0.459, \mathrm{t}=4.098, \mathrm{p}=0.000)$, $\mathrm{EE}$ is significantly related to $\mathrm{BI}(\mathrm{b}=0.126, \mathrm{t}=5.478, \mathrm{p}=0.001)$, SI is significantly related to $\mathrm{BI}(\mathrm{b}=-0.013, \mathrm{t}=0.195, \mathrm{p}=0.849)$, $\mathrm{BI}$ is significantly related to $\mathrm{UB}(\mathrm{b}=0.326, \mathrm{t}=4.639, \mathrm{p}=0.195)$. $\mathrm{BI}$ mediated between $\mathrm{PE}$ and $\mathrm{UB}(\mathrm{b}=0.096$, $\mathrm{t}=3.288, \mathrm{p}=0.000)$, BI mediated between EE and UB $(\mathrm{b}=0.096, \mathrm{t}=3.288, \mathrm{p}=0.001)$, and BI mediated between $\mathrm{SI}$ and $\mathrm{BU}(\mathrm{b}=0.035, \mathrm{t}=2.187, \mathrm{p}=0.001)$.

Moreover, PE had effect size of 0.267on BI, EE had effect size of 0.248 on BI, SI had effect size of 0.152 on $\mathrm{BI}$, and $\mathrm{BI}$ had effect size of 0.251 on BU. 
In addition to that, Stone-Geisser (Stone, 1974; Geisser, 1974) test for predictive relevance by blindfolding procedure for goodness-of-fit was followed as shown in Table 2. These values were found above zero (0.139) for BI and (0.238) for BU. which according to Henseler, Ringle, and Sinkovics (2009) shows model had good predictiveness as bearing value above 0 "Zero".

\section{DISCUSSION}

Aim of this study was to address the phenomenon of technology adaptability in the light of AI enabled IoT warble devices effectiveness for adoptability behavior through UTAUT assumptions particularly in context of developing countries. And the overall model was found to have $52 \%$ variance explained by acceptance determinants and $42 \%$ of variance explained intentional use on actual use of technology which is $10 \%$ reduced due to social influence that affected negatively over behavior to use the technology. Moreover, the study reveals the mediating effect of intention to use the technology between determinants and behavior to use the AI enabled m-health applications for wearable IoT devices technology in healthcare.

The behavior to use technology was positively influenced by the performance expectancy and effort efficiency. Whereas, the social influence negatively affects the behavioral intention of technology adoption. These effects were further carried by the behavioral intention to actual behavior of using the technology. It was noticed that social influence in developing countries was not supportive and that also reduced the actual behavior to use the technology by $10 \%$ in local context of Pakistan. This highlights the fact that in social structure of Pakistan, technology is either less trusted and still rely on physical method of getting treatment for diseases or diagnoses.

\section{CONCLUSION}

The aim of this study was to elaborate technological advancement to enable efficiency of existing healthcare services specially in developing countries. This study also reviews the potential areas that are 
enhanced in terms of technology adoption. Since, the technology holds the future of any organization, healthcare practitioners were reluctant towards technology adoption. Thus, this study focuses on important elements that might hinder clinician's technology adoption behavior.

Findings of this study beacon the direct effect of UTAUT determinants on behavioral intention of medical professionals to use new technology in healthcare system. Findings also revealed the usefulness of UTAUT model to test the behavioral intention towards M-IoT use and provides additional contribution in the literature in the role of experience and significance behavioral role in new technological adoptions.

There are certain limitations that may attract new research as this study gather viewpoint of only clinicians and focusses only public healthcare sector which might less likely to adopt technology. Further, social and cultural dimensions must be included to better asses behavior of patients and medical professionals towards technology adoption.

Typically, in developing countries like Pakistan, hospital-acquired infections are themselves a big killer. Thus, hospital management could deploy devices that monitor medical professional within hospital and patients out of hospital vicinities. Such as M-IoT based hygiene monitoring system could save million patients, time of doctors, and efficiently manage the resources. This can be reflected in current COVID-19 pandemic, where global system in all respects has collapsed, specifically the healthcare sector. And failure of healthcare is currently approximated to failure of the state machinery.

Therefore, the future of healthcare, even in emergency department, performance typically relies on connectivity of smart devices over the internet, and the transfer of information is crucial for any developed as well as developing countries like Pakistan. This research beacons the AI enabled M-IoT adoption in healthcare to benefit masses with high accuracy, effectiveness and efficiency.

\section{ACKNOWLEDGEMENT}

The authors wish to thank Hazrat Manzoor Hussain (RA). 


\section{REFERENCES}

Ajami, S., Ketabi, S., \& Torabiyan, F. (2015). Performance improvement indicators of the Medical Records Department and Information Technology (IT) in hospitals. Pakistan Fournal of Medical Sciences, 31(3), 717-720. http://dx.doi.org/10.12669/pjms.313.8005

Alemdar, H., \& Ersoy, G. (2010). Wireless sensor networks for healthcare: A survey. Computer networks, 54(15), 2688-2710. https://doi.org/10.1016/j.comnet.2010.05.003

Anurina, O. (2019). Io T Healthcare: What the Future Holds for the Healthcare Industry. https://mlsdev.com/ blog/iot-healthcare

Bagozzi, R. P. (2007). The legacy of the technology acceptance model and a proposal for a paradigm shift. Gournal of the association for information systems, 8(4), 3. https://www.researchgate. net/publication/220580454_The_Legacy_of_the_Technology_Acceptance_Model_and_a_ Proposal_for_a_Paradigm_Shift

Bernaert, A., \& Akpakwu, E. (2018). Four ways AI can make healthcare more efficient and affordable. World Economic Forum. weforum.org/agenda/2018/05/four-ways-ai-is-bringing-down-the-cost-ofhealthcare/

Bernaert, A., \& Dimitrova, D. (2017). Global healthcare: the $\$ 300$ billion question. World Economic Forum. https://www.weforum.org/agenda/2017/11/the-300-billion-global-health-question/

Birgani, G., \& Asadpoor, S. (2011). Nosocomial Infections in Intensive Care Unit of Ahwaz Arya Hospital (2008-2009). Modern Care Fournal, 8(2), 85-93. https:/ /www.sid.ir/en/journal/ViewPaper. aspx?id $=236679$

Bui, T. (2000). Building agent-based corporate information systems: An application to telemedicine. European Fournal of Operational Research, 122(2), 242-257. https://doi.org/10.1016/S03772217(99)00231-3 
Bureau of statistics planning \& development department government of Sindh. (2016). Health profile of Sindh (District wise) For the year 2016. http://sindhbos.gov.pk/wp-content/ uploads/2016/01/Health-Profile-of-Sindh-2017.pdf

Ghaffey, D. (2019). Mobile marketing statistics compilation. https://www.smartinsights.com/mobilemarketing/mobile-marketing-analytics/mobile-marketing-statistics/

Ghin, W. W. (1998). The partial least squares approach for structural equation modeling. In G. A. Marcoulides (Ed.), Methodology for business and management. Modern methods for business research (p. 295336). Lawrence Erlbaum Associates Publishers. https://psycnet.apa.org/record/1998-07269-010

Gimperman, M., Makovec, M., \& Trkman, P. (2016). Analyzing older users' home telehealth services acceptance behavior - applying an Extended UTAUT model. International fournal of Medical Informatics, 90, 22-31. https://doi.org/10.1016/j.ijmedinf.2016.03.002

Gurioni-Fontecedro, A. (2017). A new era of oncology through artificial intelligence. http://dx.doi. org/10.1136/esmoopen-2017-000198

Dargazany, A. R., Stegagno, P., \& Mankodiya, K. (2018). WearableDL: Wearable Internet-ofThings and Deep Learning for Big Data Analytics - Concept, Literature, and Future. Mobile Information Systems. Article ID 8125126. https://doi.org/10.1155/2018/8125126

Elazhary, H. (2019). Internet of Things (IoT), mobile cloud, cloudlet, mobile IoT, IoT cloud, fog, mobile edge, and edge emerging computing paradigms: Disambiguation and research directions. Fournal of Network and Computer Applications, 128, 105-140. https://doi.org/10.1016/j.jnca.2018.10.021

Hair, J. F., Hult, G. T. M., Ringle, G., \& Sarstedt, M. (2016). A primer on partial least squares structural equation modeling (PLS-SEM). Sage publications. 
Henseler, J., Dijkstra, T. K., Sarstedt, M., Ringle, C. M., Diamantopoulos, A., Straub, D. W., Ketchen, D. J., Hair, J. F., Hult, T. M., \& Calantone, R. J. (2014). Common beliefs and reality about PLS: Comments on Rönkkö and Evermann (2013). Organizational Research Methods, 17(2), 182209. https://doi.org/10.1177/1094428114526928

Henseler, J., Ringle, C. M., \& Sarstedt, M. (2015). A new criterion for assessing discriminant validity in variance-based structural equation modeling. Fournal of the Academy of Marketing Science, 43(1), 115-135. https://doi.org/10.1007/s11747-014-0403-8

Henseler, J., Ringle, C. M., \& Sinkovics, R. R. (2009). The use of partial least squares path modeling in international marketing. In Sinkovics, R. R. and Ghauri, P. N. (Ed.) New Challenges to International Marketing (Advances in International Marketing, Vol. 20), Emerald Group Publishing Limited, Bingley, 277-319. https://doi.org/10.1108/S1474-7979(2009)0000020014

Islam, S. M. R., Kwak, D., Kabir, M. H., Hossain, M., \& Kwak, K. S. (2015). The internet of things for health care: a comprehensive survey. IEEE Access, 3, 678-708. https://ieeexplore.ieee. org/document/7113786

Jahns, R.-G., \& Houck, P. (n.d.). Mobile Health Market Report 2013-2017. https://research2guidance. com/product/mobile-health-trends-and-figures-2013-2017/

Karaca, Y., Moonis, M., Zhang, Y. D., \& Gezgez, G. (2019). Mobile cloud computing based stroke healthcare system. International fournal of Information Management, 45, 250-261. https://doi. org/10.1016/j.ijinfomgt.2018.09.012

Khan, S. A. (2019). Situation Analysis of Health Care System of Pakistan: Post 18 Amendments. Health Care: Current Reviewes, 7(3). https://www.longdom.org/open-access/situation-analysis-of-healthcare-system-of-pakistan-post-18-amendments-44119.html 
Krejcie, R. V., \& Morgan, D. W. (1970). Determining sample size for research activities. Educational and psychological measurement, 30(3), 607-610. https://journals.sagepub.com/doi/ abs/10.1177/001316447003000308

Kurji, Z., Premani, Z. S., \& Mithani, Y. (2016). Analysis of the health care system of Pakistan: lessons learnt and way forward. Fournal of Ayub Medical College, Abbottabad, 28(3), 601-604. https:// pubmed.ncbi.nlm.nih.gov/28712245/

Ma, X., Wang, Z., Zhou, S., Wen, H., \& Zhang, Y. (2018). Intelligent healthcare systems assisted by data analytics and mobile computing. Wireless Communications and Mobile Computing. Article ID 3928080. https://doi.org/10.1155/2018/3928080

Malkani, S. (2016). Pakistan's healthcare crisis. https://www.dawn.com/news/1267410

Malliarou, M., \& Zyga, S. (2009). Advantages of Information Systems in Health Services. Choregia, 5(2), 43-54. https://www.ingentaconnect.com/content/doaj/17914027/2009/00000005/00000 $002 / \operatorname{art} 00003$

Meara, J. G., Leather, A. J., Hagander, L., Alkire, B. C., Alonso, N., Ameh, E. A., Bickler, S. W., Conteh, L., Dare, A. J., Davies, J., Mérisier, E. D., El-Halabi, S., Farmer, P. E., Gawande, A., Gillies, R., Greenberg, S. L., Grimes, G. E., Gruen, R. L., Ismail, E. A., ... \& Yip, W. (2015). Global Surgery 2030: evidence and solutions for achieving health, welfare, and economic development. The Lancet, 386(9993), 569-624. https://doi.org/10.1016/S0140-6736(15)60160-X

Meskó, B., Hetényi, G., \& Győrffy, Z. (2018). Will artificial intelligence solve the human resource crisis in healthcare? BMC Health Services Research, 18, 545. https://doi.org/10.1186/s12913-0183359-4

Mirhoseinie, M., Ziadloo, D., Nasirie, N., \& Sayerinia, A. (2014). Knowledge and Attitude of Health Care Workers Providing Services in Kerman University of Telemedicine. In Bioresonanse and Modern medical diagnoses. Medical Council country eHealth Institute. 
Mitzner, T. L., Boron, J. B., Fausset, G. B., Adams, A. E., Charness, N., Gzaja, S. J., Dijkstra, K., Fisk, A. D., Rogers, W. A., \& Sharit, J. (2010). Older Adults Talk Technology: Technology Usage and Attitudes. Computers in human behavior, 26(6), 1710-1721. https://doi.org/10.1016/j. chb.2010.06.020

Mohamed, A. H. H., Tawfik, H., Norton, L., \& Al-Jumeily, D. (2011, April). e-HTAM: A Technology Acceptance Model for electronic health. In 2011 International Conference on Innovations in Information Technology, Abu Dhabi, United Arab Emirates, 134-138. https://doi.org/10.1109/ INNOVATIONS.2011.5893804

Nazir, S., Ali, Y., Ullah, N., \& García-Magariño, I. (2019). Internet of Things for Healthcare Using Effects of Mobile Computing: A Systematic Literature Review. Wireless Communications and Mobile Computing. Article ID 5931315. https:/ / doi.org/10.1155/2019/5931315

Pearson, T. (2011). How to replicate Watson hardware and systems design for your own use in your basement. https://www.ibm.com/developerworks/community/blogs/InsideSystemStorage/entry/ibm_ watson_how_to_build_your_own_watson_jr_in_your_basement7?lang=en

Qi, J., Yang, P., Min, G., Amft, O., Dong, F., \& Xu, L. (2017). Advanced internet of things for personalised healthcare systems: A survey. Pervasive and Mobile Computing, 41, 132-149. https://doi. org/10.1016/j.pmcj.2017.06.018

Rothenhaus, T., Kamens, D., Keaton, B. F., Nathanson, L., \& Nielson, J. (2009). Information Systems For Emergency Care, Primer For Emergency Physicians, Nurses, And IT Professionals. American College of Emergency Physicians White Paper Report, 22, 1-30.

Safi, S., Thiessen, T., \& Schmailzl, K.J. (2018). Acceptance and resistance of new digital technologies in medicine: qualitative study. FMIR research protocols, 7(12), e1 1072. https://pubmed.ncbi.nlm.nih. gov/30514693/ 
Samad, D., Al-Athwari, A., \& Hussain, A. (2019). Usability Evaluation of Mobile Health Application from AI Perspective in Rural Areas of Pakistan. International Fournal of Interactive Mobile Technologies (ifIM), 13(11), 213-225. https://www.researchgate.net/publication/338825533_Usability_ Evaluation_of_Mobile_Health_Application_from_AI_Perspective_in_Rural_Areas_of_Pakistan

Samad, A., Memon, S. B., \& Kumar, M. (2020) Job satisfaction among nurses in Pakistan: The impact of incivility and informal climate. Global Business and Organizational Excellence: a Review of Research \& Best Practices, 39(4), 53-59. https://doi.org/10.1002/joe.22004

Sannino, G., Bouguila, N., De Pietro, G., \& Celesti, A. (2019). Artificial intelligence for mobile health data analysis and processing. Mobile Information Systems, (1-2). https://www.researchgate. net/publication/330562313_Artificial_Intelligence_for_Mobile_Health_Data_Analysis_and_ Processing

Shaikh, K. A. (2019). What we knows of IoT devices \& applications. https://www.pakistaneconomist. com/2019/11/25/what-we-knows-of-iot-devices-applications/

Siamian, H., Gonbadi, K., Nasiri, E., \& Shahrabi, A. (2005). Health information management role in hospital management. Electronic Journal Irn Scien Information and Documentation, 4(3), 19-28.

Siltala, M. (2013). Is mobile healthcare the future? Infographic journal. https://infographicjournal.com/ is-mobile-healthcare-the-future/

Singh, S. (n.d.). Io T in Healthcare Market worth $\$ 188.0$ billion by 2024. https://www.marketsandmarkets. $\mathrm{com} /$ PressReleases/iot-healthcare.asp

Solangi, Z. A., Aziz, M. S., Hamzah, M. S., \& Shah, A. (2017a). Reliability and validity of a questionnaire for empirical analysis of factors influencing IOT-based smart healthcare. https://www.researchgate.net/ publication/327396019_RELIABILITY_AND_VALIDITY_OF_A_QUESTIONNAIRE_ FOR_EMPIRICAL_ANALYSIS_OF_FACTORS_INFLUENCING_IOT-BASED_SMART_ HEALTHCARE 
Solangi, Z. A., Solangi, Y. A., Aziz, M. S. A., \& Shah, A. (2017b). An empirical study of Internet of Things (IoT) - Based healthcare acceptance in Pakistan: PILOT study. In 2017 IEEE 3rd International Conference on Engineering Technologies and Social Sciences (ICETSS), Bangkok, Thailand (pp. 1-7). https://doi.org/10.1109/ICETSS.2017.8324135

Strasser, R., Kam, S. M., \& Regalado, S. M. (2016). Rural health care access and policy in developing countries. Annual Review of Public Health, 37, 395-412. https://doi.org/10.1146/ annurev-publhealth-032315-021507

Subasi, A., Radhwan, M., Kurdi, R., \& Khateeb, K. (2018). IoT based mobile healthcare system for human activity recognition. In 2018 15th Learning and Technology Conference (LET), Jeddah, Saudi Arabia (pp. 29-34). https://doi.org/10.1109/LT.2018.8368507

Tyagi, S., Agarwal, A., \& Maheshwari, P. (2016). A conceptual framework for IoT-based healthcare system using cloud computing. In 6th International Conference - Cloud System and Big Data Engineering (Confluence), Noida, India, 503-507. https://doi.org/10.1109/CONFLUENCE.2016.7508172

Van der Meulen, R. (2017). Gartner Says 8.4 Billion Connected "Things" Will Be in Use in 2017, Up 31 Percent From 2016. Gartner. https://www.gartner.com/en/newsroom/press-releases/2017-02-07gartner-says-8-billion-connected-things-will-be-in-use-in-2017-up-31-percent-from-2016

Venkatesh, V., Morris, M. G., Davis, G. B., \& Davis, F. D. (2003). User acceptance of information technology: Toward a unified view. MIS quarterly, 27(3), 425-478. https://misq.org/useracceptance-of-information-technology-toward-a-unified-view.html

Venkatesh, V., Thong, J. Y., \& Xu, X. (2016). Unified theory of acceptance and use of technology: A synthesis and the road ahead. Fournal of the Association for Information Systems, 17(5), 328-376. https://doi.org/10.17705/1jais.00428

Wallace-Wells, B. (2020). The Coming Coronavirus Critical-Care Emergency. The New Yorker. https:/ /www. newyorker.com/news/news-desk/the-coming-coronavirus-critical-care-emergency 
World Health Organization. (2013). A Universal Truth: No health without a workforce. https://www.who. int/workforcealliance/knowledge/resources/GHWA_AUniversalTruthReport.pdf

Yuehong, Y. I. N., Zeng, Y., Ghen, X., \& Fan, Y. (2016). The internet of things in healthcare: An overview. Fournal of Industrial Information Integration, 1, 3-13. https://doi.org/10.1016/j. jii.2016.03.004

Zaidi, S. (2012). Sindh health sector strategy 2012 - 2020. Government of Sindh, 1-124. http:/ / ecommons. aku.edu/pakistan_fhs_mc_chs_chs/213 